\title{
Post-Cold War United Nations Peacekeeping Operations: A Review of the Case for a Hybrid Level 2+ Medical Treatment Facility: Commentary
}

\section{Lieutenant Colonel Ralph Jay Johnson III*}

Lieutenant Colonel Ralph Jay Johnson III, United States Army LTC Medical Operations and Planning Officer, HQ, USARPAC, G-3, BIdg. T, 117, ATTN: APAG-RC, Ft. Shaftner, HI, 96858, USA

This article reports an evidence-based study suggesting that a hybrid level $2+$ Medical Treatment Facility (MTF) augmented modularly with proper medical services is optimal for meeting the many and varied medical care challenges of Post-Cold War United Nations Peace Keeping Operations (UN PKOs). Nevertheless, the important untold story was the methodology used through which its conclusions were reached.

\section{My intent in the article was 3-fold}

(1)Argue that Post-Cold War there has been a dramatic and fundamental change in the conditions, missions, and consequently the operations and tempo for UN PKOs, which requires an ensuing shift in their medical support.[1-3]

(2)Report my evidence-based investigation and analysis on UN PKOs borrowed from Nessen [4] who had originally used it in terms of medical military support of U.S. military forces in the Iraq war to test the viability of Level 2+ MTF there. (Note: Technical transfer and testing of a hypothesis under varying conditions is the essence of scientific inquiry.) However, I found completely different results on the viability of a Level 2+ MTF in terms of Post-Cold War UN PKOs unlike what Nessen found regarding US medical support regarding Iraq war operations.

(3)Describe the results from practical applications of process models with promising and worthwhile implications in terms of informing planning, preparing, vetting, and execution of medical support operations for future UN PKOs whatever their particular circumstances.

First, there are apologists who claim that overall UN PKOs have not changed with inferences that there is no need to alter their medical support.[5] Their assertions are based on lumping together Pre-Cold War and Post-Cold War UN PKOs and regressing to the mean without consideration for extremes or any regard to PKO type. During the Cold War, with the exception of UN PKOs in the Congo, UN PKOs were relatively benign affairs with impartial, unarmed peace observers or lightly armed peacekeepers inter-positional-ly separating belligerents who consented to the peace process, until there was a peaceful resolution of hostilities. [6-7] Thus, medical events reflected the overall character of Pre-Cold War missions and were also relatively benign and those typically associated with non-combat deployment, such as, orthopedic conditions, respiratory diseases, and the flu.[8-9] Thus, medical support was relatively fixed/static, relying heavily on rearward transport/treatment and there was a nagging lack of mobile facilities to treat emergencies in forward operating areas.

Nevertheless, as my article notes, UN PKOs changed drastically in the Post-Cold War. Post-Cold War UN PKOs became complex nation (re-)building affairs that were highly mobile, with combat like actions (i.e., "robust" and "robust + "), in places with simmering internecine armed conflicts about to boil over, where some belligerents had not consented to the peace process, and the PKOs could potentially degenerate into dangerous and ugly/hideous affairs (e.g., Kosovo, Rwanda, Somalia, etc...). Furthermore, these operations were being conducted in some of the world's most rugged, remote, inhospitable, and untamed peripheries.[10-16] These PKOs only had a thin veneer of traditional UN peacekeeping.[16] Likewise, Post-Cold War UN PKO medical events increasingly have resembled combat-like emergency trauma and psychological disorders accompanied by exotic and debilitating diseases.[17-22] Therefore, as my article noted, the challenge for planning medical support has been and is anticipated to be similar to those found in dynamic other-than-war combat operations, specifically, balancing pushing forward patient care while risking medical personnel/assets versus reward patient transport to care with risk to patients.[23-25]

Second, in proposing a possible solution to this challenge, my article reports an evidence-based test on UN PKOs that I borrowed from Nessen [4] who originally conducted it on the necessity and viability of a modularly modified Level $2+$ Medical Treatment Facility in terms of providing medical support in the Iraq combat theater. $\mathrm{He}$ found it untenable for Iraq combat operations. Yet as my article reports, given UN PKOs Post-Cold War missions and under the conditions in which they have been operating, I found just such a properly modularly augmentable MTF a potentially practical and viable alternative. It would be capable of delivering responsive mobile, properly varied, and commensurate medical care in tandem with forward troop movement and responsive to mission necessities and contingenciesespecially trauma care and psychiatric and preventive medicine. Thus, an important aspect of my article is that it reports far different, positive, and promising findings from empirical testing conducted on military medical support on Post-Cold War UN PKOs. It used a test borrowed from work done on another military setting with somewhat different conditions (the Iraq War) that had negative and discouraging results. This is the epitome of scientific inquiry, specifically, systematic empirical hypothesis testing under varying conditions to determine whether outcomes are consistent.

Third, and thus, the crucial importance of my article is not only its conclusions about the viability of a modularly modified Level 2 + Medical Treatment Facility for Post-Cold War UN PKOs, but also the untold story of the methods used with which to arrive at those conclusions. Also, important are the implications or logical extension

${ }^{*}$ Corresponding author: Lieutenant Colonel Ralph Jay Johnson III, United States Army LTC Medical Operations and Planning Officer, HQ, USARPAC, G-3, Bldg. T, 117, ATTN: APAG-RC, Ft. Shaftner, HI, 96858, USA, Tel: 832-372-3511; E-mail: Ralph.J.johnson16.mil@mail.mil

Received July 24, 2014; Accepted September 18, 2015; Published Septembe 25, 2015

Citation: Jay Johnson III LCR (2015) Post-Cold War United Nations Peacekeeping Operations: A Review of the Case for a Hybrid Level 2+ Medical Treatment Facility: Commentary. Health Care Current Reviews 3: 136. doi: 10.4172/23754273.1000136

Copyright: ( 2015 Jay Johnson III LCR. This is an open-access article distributed under the terms of the Creative Commons Attribution License, which permits unrestricted use, distribution, and reproduction in any medium, provided the original author and source are credited. 


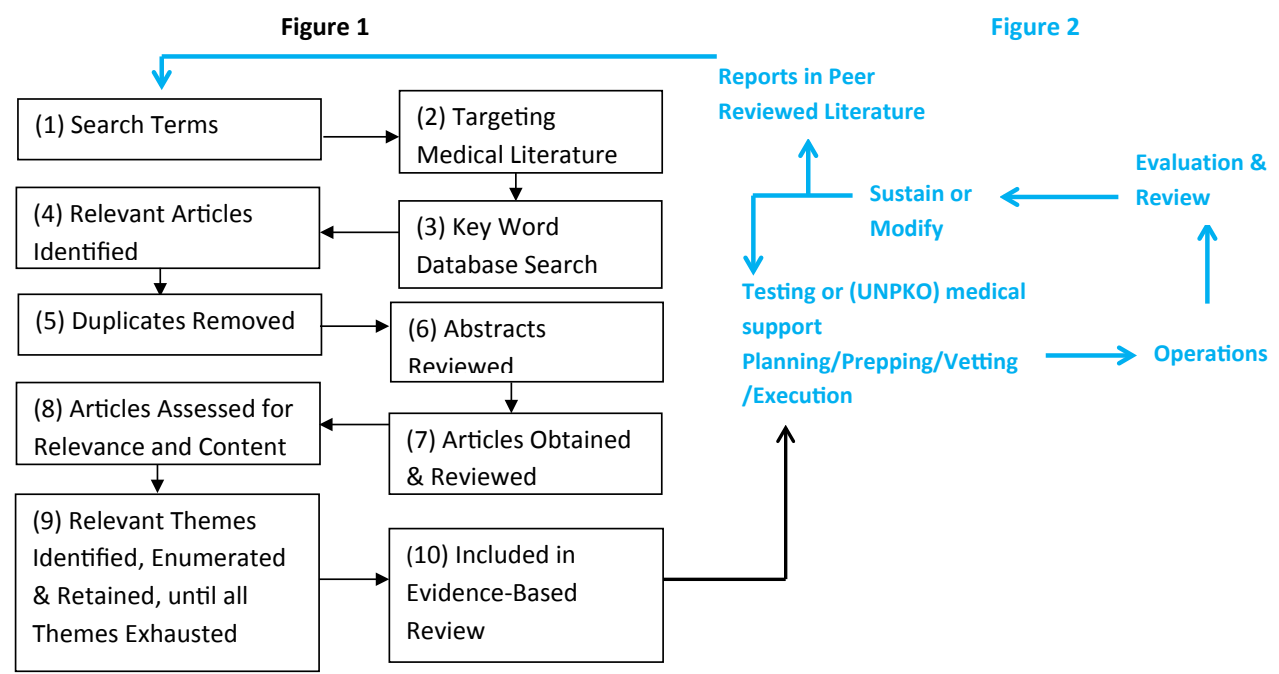

Figure 1 and 2: Figure 1 (Researching to Inform Testing or Planning) and Figure 2 (Post-Cold War UNPKO medical support Testing or Planning/Prepping, Vetting, Executing, and Programmatic Evaluation and Modification).

of those methods for UN PKO medical support planning, prepping, vetting, and executing. The paramount lesson in my article is one size and a simple fix will not solve or fix all. Post-Cold war UN PKOs have become complex and multi-faceted undertakings. Therefore, their medical support planning must be purpose built for each operation and subsequently modified as those operations unfold. Their planning processes must be comprehensively researched and provide initial speedy reaction combined with evidence-based programmatic evaluation and trial and error modification during their execution. This is best displayed in the following diagrams.

Figure 1 depicts the evidence-based and best practices research process that informed my work through which open-sourced articles were identified then reviewed and conceptual themes generated and on which the idea of a Level $2+$ MTF was tested. This approach can just as easily inform UN PKO medical support planning or even other planning processes.

Essentially, this figure conveys the steps in this process. Step one involved deriving key words with which to search for articles. Step two is targeting appropriate peer-reviewed medical/health and military subject matter databases. Step three is applying the search terms to the databases. Steps four and five are the identification, retrieval of relevant articles, and removal of duplicates. Step six is retrieval and review of abstracts or executive summaries. Step seven is obtaining the articles and step eight reviewing their content for relevance. Step nine is identification and enumeration of themes and the retrieval of related information for review until all themes were exhausted with the outcome, step ten, the review. Given the process is "theoretically grounded" [26], though the steps are generally sequential, they could be repeated individually, or there could be cycling back and forth between steps or cycling back through the process. But the eventual and ultimate aim is the identification, summation and exhaustion of all themes.

This then was fed into () a test of the viability and practicality of the Level 2+ MTF. It could just as easily be fed into the UN PKO medical support Planning-Prepping-Vetting-Execution-Modification process (Figure 2), which is cyclic and virtually self-explanatory. (It also could be used to inform other UN PKO planning processes.)

Note: For actual in-country operations planning-along with a grounded iterative scouring of the literature-there must a "leaders' reconnaissance" and a "terrain walk." Namely, beforehand, reliable eyes or sets of eyes must conduct an actual "boots-on-the-ground," close-aspossible-to-real-time survey of the conditions in which a proposed UN PKO will be conducted. This can then be compared with the literature to breathe life into findings from the paper reports, fill in critical gaps or grey areas or Requests for Information (RFIs), and determine the veracity of the literature.

In sum, the most profound implication in my article is that the processes depicted in these figures should be incorporated into a UN PKO strategic medical planning mind-set. This is the first step. The next step is formal reporting in the literature where there is a such a void of systematic research on medical aspects of UN PKOs. By that void's very existence, it begs to be filled by high-quality, peer-reviewed credible evidence-based findings-with which to inform planners and policy makers so they can craft high-impact planning and policy.

\section{Author bio}

LTC Ralph J Johnson is currently is serving as an Embedded Technical Trainer and Medical Plans and Operations officer, Medical Operations and Planning, HQ, USARPAC, G-3. Also, he works with the University of Texas-MDACC and TMC CCC at St. Luke's Hospital and Baylor College of Medicine in the Texas Medical Center in Houston, Texas.

\section{Conflicts of Interest}

The Author reports no conflicts of interest. The author gratefully thanks the University of the Texas Houston Health Science Center MDACC and U.S. Army Reserves for material support. Neither institution nor agency had any involvement in study design; collection, analysis, and interpretation of data; writing the report; and the decision to submit the report for publication.

\section{Author's Note}

The work and opinions expressed herein are solely those of the author. The author thanks Mr. (COL) Karl Farris and Mr. (COL) George Oliver for their advice and guidance and encouragement on that project that culminated in this manuscript. The author gratefully acknowledges COL SC Nessen for his work that provided the basis to test the ideas of his hypothesis on UN peacekeeping missions. 
Citation: Jay Johnson III LCR (2015) Post-Cold War United Nations Peacekeeping Operations: A Review of the Case for a Hybrid Level 2+ Medical Treatment Facility: Commentary. Health Care Current Reviews 3: 136. doi: 10.4172/2375-4273.1000136

\section{References}

1. Johnson RJ ( 2014) Medical Aspects of UN Peacekeeping Operations Trends, Courses of Action, and Recommendations. Thesis report presented in partial fulfillment of the COTIPSO program.

2. Johnson RJ 3rd (2015) A literature review of medical aspects of post-cold war UN peacekeeping operations: trends, lessons learnt, courses of action and recommendations. J R Army Med Corps .

3. Johnson RJ (2015) A review of supplementary medical aspects of post-cold war UN peace keeping operations: Trends, Lessons Learnt, Courses of Action and Recommendations. AMEED Journal (Inpress)

4. Nessen SC (2005) The Mobile Modular Surgical Hospital The Army medica Department's Future Unit of Action. Thesis presented to the U.S. Army Command and Staff College.

5. Wong A, Escobar M, Lesage A, Loyer M, Vanier C, et al. (2001) Are UN peacekeepers at risk for suicide? Suicide Life Threat Behav 31: 103-112.

6. Ram S (2008) History of United Nations peacekeeping operations during the Cold War 1945 to 1987 (series edn. Harvey J. Langholtz, Ph.D.). Williamsburg, VA Peace Operations Training Institute 1-42.

7. Gordon R Gen (2010) Principles and guidelines for UN peacekeeping operations (series edn. Harvey J. Langholtz, Ph.D.). Williamsburg, VA Peace Operations Training Institute19-49.

8. cf. McKee KT, Kortepeter MG, Liaamo SK (1998) Disease and non-battle injury among United States soldiers deployed in Bosnia-Herzegovina during 1997 Summary primary care statistics for Operation Joint Guard. Mil Med 163: 733742.

9. Kocik J, Niemcewicz M, Winnicka I, Michalski A, Bielawska-Drózd A et al. (2014) Diversity of influenza-like illness etiology in Polish Armed Forces in influenza epidemic season. Acta Biochim Pol 61: 489-494.

10. Ram S (a) (2008) History of United Nations peacekeeping operations from retrenchment to resurgence 1997 to 2006 (series ed. Harvey J. Langholtz, Ph.D.). Williamsburg, VA Peace Operations Training Institute 1-6.

11. Hårleman C Lt, Col (2011) An introduction to the UN system: Orientation for serving on a UN field mission (series edn. Harvey J, Langholtz, Ph.D.). Williamsburg, VA Peace Operations Training Institute 6:128-129.

12. Sheik M, Gutierrez MI, Bolton P, Spiegel P, Thieren M, et al. (2000) Deaths among humanitarian workers. BMJ 321: 166-168.
13. Pugh M (1998) Military intervention and humanitarian action: trends and issues. Disasters 22: 339-351.

14. Seet B (2001) Increased humanitarian deaths may not mean higher risks of dying. BMJ 322: 300-301

15. Seet B, Burnham GM (2000) Fatality trends in United Nations Peacekeeping Operations, 1948-1998. JAMA 284: 598-603.

16. Durch WJ, Berkman TC (2006) Restoring and Maintaining Peace (1-49) in 21st Century Peace Operations (WJ Durch edn.), United States Institute for Peace The Henry L. Stimson Center Washington, D.C 1-9, and 33 -39.

17. Raju MS (2014) Psychological aspects of peacekeeping operations. Ind Psychiatry J 23: 149-156.

18. Thomassen ÅG, Hystad SW, Johnsen BH, Johnsen GE, Laberg JC, et al (2015) The combined influence of hardiness and cohesion on mental health in a military peacekeeping mission: A prospective study. Scand J Psychol 56: 560-566.

19. Connorton E, Perry MJ, Hemenway D, Miller M (2011) Occupational trauma and mental illness--combat, peacekeeping, or relief work and the national comorbidity survey replication. J Occup Environ Med 53: 1360-1363.

20. Mehlum L, Koldsland BO, Loeb ME (2006) Risk factors for long-term posttraumatic stress reactions in unarmed UN military observers: a four-year follow-up study. J Nerv Ment Dis 194: 800-804.

21. Juliao PC, Sosa S, Gonzalez LD, Padilla N, Ortiz L, et al. (2013) Importation of chloroquine-resistant Plasmodium falciparum by Guatemalan peacekeepers returning from the Democratic Republic of the Congo. Malar J 23 12:344.

22. Connor P, Porter CK, Swierczewski B, Riddle MS (2012) Diarrhoea during military deployment: current concepts and future directions. Curr Opin Infect Dis 25: $546-554$.

23. cf. Smadi RM, Smadi BY (2004) Medical aspects of United Nations Peace Keeping Missions A Six-month-experience in Eriteria JRMS 11: 68-71.

24. cf. Joshi VV Wg CDR (2003) United Nations mission in Sierra Leone (UNAMSIL) Medical deployment and experiences. Ind J Aerospace Med 47: 51-62.

25. Reade MC Cpt (2002) Medical support for British peacekeeping operations in Kosovo (UNMIK/KFOR).71-76.

26. Corbin JL, Strauss AL (2008) Basics of qualitative research Grounded Theory and procedures (3rd edn). Thousand Oaks, CA Sage 87-223. 